\title{
The influence of mechanical resistance and phosphate supply on morphology and function of maize roots
}

\author{
F. R. Boone ${ }^{1}$ and B. W. Veen ${ }^{2}$ \\ ' Tillage Laboratory, Agricualtural University, Wageningen, Netherlands \\ ${ }^{2}$ Centre for Agrobiological Research (CABO), Wageningen, Netherlands
}

Accepted: 19 February 1982

Key-words: soil compaction, root development, phosphate supply, mechanical resistance, nitrogen uptake, phosphorus uptake, potassium uptake, maize

\section{Summary}

In three pot experiments maize was grown on a marine sandy loam compacted to different pore volumes and supplied with different amounts of phosphate.

It appeared that root weight was not changed by different levels of mechanical resistance but that root extension growth and cone resistance were curvilinearly related. At high mechanical resistance the root growth direction was more horizontal. As a consequence of those two factors root growth to depth was very limited at high cone resistances. Moreover the specific root length was smaller and root diameter larger. Under our experimental conditions less laterals per $\mathrm{cm}$ main root were developed, whereas the average length of these laterals was not influenced. The influence of mechanical resistance on root distribution and morphology reduces the uptake of nutrients and concomitantly shoot growth, if a nutritional factor is limiting. In our experiments, at low phosphate availability, phosphate was more limiting shoot growth, the higher the mechanical resistance was. At a sufficient phosphate supply the same effect on potassium was observed. If an above-ground factor, such as a low light intensity, is limiting shoot growth, there is no influence of mechanical resistance on shoot growth.

Uneven distribution of roots in soil can give rise to depletion of nutrients in the upper soil layers. When explaining the relation between root development and ion uptake the availability of nutrients in the different soil layers must be taken into consideration.

\section{Introduction}

The influence of root development on ion uptake, and the influence of conditions in the root environment on ion uptake and root development has been extensively studied with nutrient solutions as a rooting medium. From an agricultural point of view root development is considered an important factor deter- 
mining crop yield, and therefore many methods have been developed for the measurement of root systems in soil (Böhm, 1979), but there is still a lack of insight into the quantitative relation between root development and ion uptake in soil.

Comparison of ion uptake rates from nutrient solution and from soil is complicated by differences in root morphology and different limiting factors for ion uptake. Mechanical resistance of the soil is considered as the main factor determining the morphological differences between roots grown in soil and in nutrient solution (Barley, 1962). In agricultural practice differences in root growth and morphology can be influenced by tillage.

The aim of our experiments was to study the influence of mechanical resistance on root growth and morphology and subsequent ion uptake and shoot growth of maize. In order to make root development a rate limiting factor for ion uptake, phosphate was supplied in sub-optimal concentrations in part of the experiments.

\section{Materials and methods}

Three comparable experiments were carried out, in which the conditions with respect to one growth factor were different. Only the second experiment will be described completely; deviations in the other experiments will be mentioned when important in this context.

For the experiments soil was taken from the $\mathrm{C}$ horizon (sub-soil) of a marine sandy loam with a clay content $(<2 \mu \mathrm{m})$ of about $11 \%$. This soil was chosen because of its low phosphate content, the very low amount of organic material from previous crops that could disturb root measurements and because it could easily be washed from the roots. The soil was sieved through a $10-\mathrm{mm}$ sieve. Fertilizer was added and homogenized throughout the soil. The contents of $\mathrm{NO}_{3}-\mathrm{N}$ and $\mathrm{K}$ in the fertilized soil were 50 and $700 \mathrm{mg} / \mathrm{kg}$ soil respectively. $\mathrm{P}$ was added as superphosphate. The $P$ availability was measured as $P_{w}$ value $\left(\mathrm{mg}_{2} \mathrm{O}_{5} \mathrm{dm}^{-3}\right.$ soil; van der Paauw, 1971). Because of the absorptive characteristics of the soil, measurements of $P_{w}$ values were done about 4 weeks after fertilization, at the end of the experimental period. The pots were filled in layers of $3 \mathrm{~cm}$ and compacted with a hydraulic press to the desired pore volume. Between two pressings the soil surface was roughened to get a homogeneous soil structure. Five pore volumes were used: $60,51,46,44$ and $42 \%$, which resulted, at a soil moisture content of $18 \%(\mathrm{w} / \mathrm{w})$, in a penetrometer resistance of $0.3,0.9,1.6,2.3$, and 3.0 MPa respectively. At the smallest pore volume the air content of the soil was still $15 \%$ and the oxygen diffusion rate (ODR) $100 \times 10^{-8} \mathrm{~cm}^{-2} . \mathrm{min}^{-1}$ which garanteed a sufficient oxygen supply to the roots (Boone, unpublished results). The moisture content was kept as close to $18 \%$ as possible by daily weighing of the pots and adding 1.5 times the observed evapotranspiration. The estimated plant weights were taken into account.

Maize seeds, cv. Avanti, were sown in cylindrical pots (diameter $14 \mathrm{~cm}$, height $27 \mathrm{~cm}$ ) in 1-cm deep holes directly in the compacted soil. In the first experiment 
a 1-cm thick seedbed was placed on top of the compacted soil. This method was abandoned in the other experiments because of the preference of roots to grow in the seedbed. The first experiment was done in a climate room at a light intensity of $70 \mathrm{~W} \mathrm{~m}^{-2}$ for $16 \mathrm{~h}$ per day. The second experiment was done under summer conditions (daily net radiation about $10 \mathrm{MJ} \mathrm{m}^{-2}$ ) whereas the third experiment was done in autumn (daily net radiation about $3.5 \mathrm{MJ} \mathrm{m}^{-2}$ ). During all experiments the temperature was about $22^{\circ} \mathrm{C}$ and the relative humidity $70 \%$. The plants were rotated on turntables to eliminate positional differences. The first harvest was 14 days after plant appearance, the second harvest 7 days later. Shoot fresh and dry weight were measured and N, P and K content of the shoot were analysed. The soil cylinder was pressed out of the pot and cut into $3-\mathrm{cm}$ thick slices, from which the roots were washed on a fine sieve. After a final cleaning by hand the roots were wrapped in a cloth and centrifuged in a household centrifuge, after which the fresh weight was measured. Root lengths were measured by the line intersect method of Newman (1966), and root diameters with a binocular.

\section{Results}

\section{Root growth}

Root weight. The fresh weight of the root system is hardly influenced by the mechanical resistance of the soil (Figs 1 and 3). Only at a very low phosphate level there is a small negative effect of the mechanical resistance on root weight. At a high light intensity the positive effect of phosphate on root weight is very clear (Fig. 2). The relation between root fresh weight and phosphate availability is a saturation curve. Optimal root growth appears to be at $P_{w}=40$. At a low light intensity root weight is much smaller, both absolute as relative to shoot weight as can be concluded from a comparison of Fig. 1 and Fig. 3. Moreover there is no visible influence of phosphate supply on root fresh weight at a low light in-

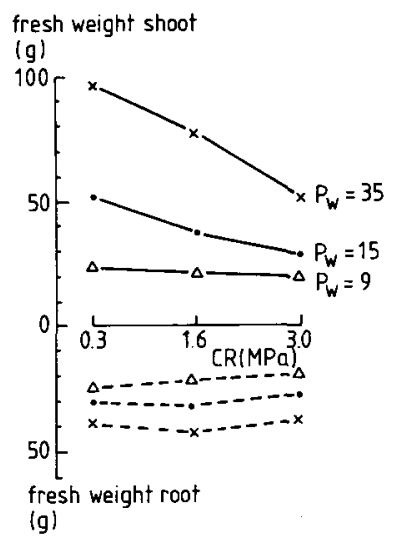

Neth.J. agric. Sci.30(1982)
Fig. 1. Influence of soil mechanical resistance (CR) on fresh weight of shoots and roots of maize three weeks after emergence at three levels of phosphate availablility $\left(\mathrm{P}_{\mathrm{w}}\right)$ under optimal light conditions. 


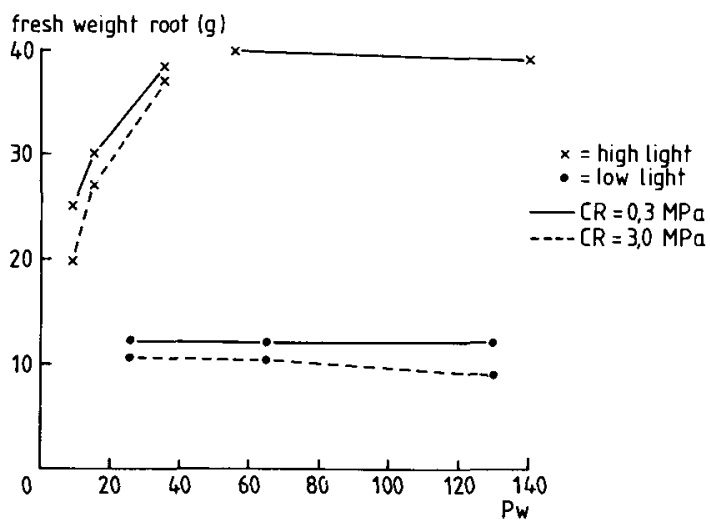

Fig. 2. The fresh weight of maize roots in relation to phosphate availability at two light intensities and two mechanical resistances.

tensity (Fig. 2), which means that root growth is more limited by light than by phospate.

Root distribution. At a low mechanical resistance of the soil there is a fairly even distribution of roots with depth, but at a high mechanical resistance roots accumulate in the upper soil layers and most roots fail to penetrate into deeper layers (Fig. 4). As a consequence there are hardly any roots at the bottom of the pot. Partly this can be explained by a low root growth velocity at a high mechanical resistance of the soil (Fig. 5) which was determined by measuring the extension growth rate of the primary root axis. Especially at moderate mechanical resistance root growth is very sensitive to changes in mechanical resistance. Between a cone resistance of 0.9 and $1.6 \mathrm{MPa}$ there is a $50 \%$ decrease in root elongation. At higher or lower cone resistance the effect is much weaker. A second phenomenon influencing the distribution of roots in soil is their growth direction. The primary axis grows vertical but the other seminal axes and the crown roots initially grow at an angle to the vertical which depends on the environmental con-

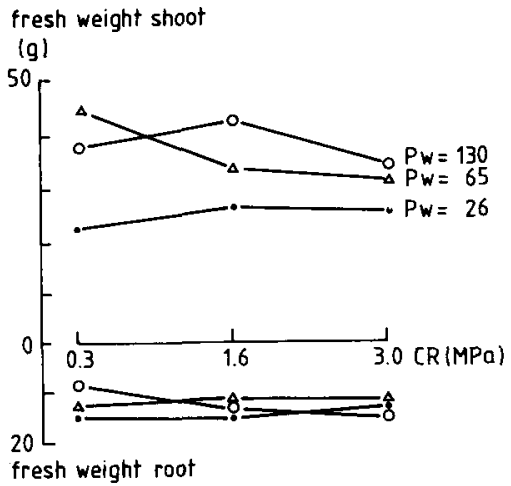

(g)
Fig. 3. Influence of soil mechanical resistance (CR) on fresh weight of shoots and roots of maize, three weeks after emergence at three levels of phosphate availability $\left(\mathrm{P}_{\mathrm{w}}\right)$, under low light conditions: 
fresh weight root

(g)

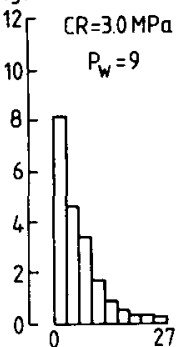

${ }^{8} \mathrm{CR}=0.3 \mathrm{MPa}$

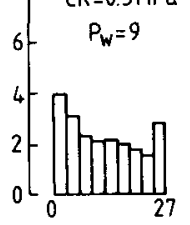

$C R=3.0 \mathrm{MPa}$

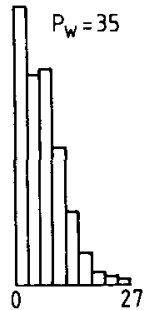

$C R=0.3 \mathrm{MPa}$

$P_{w}=35$

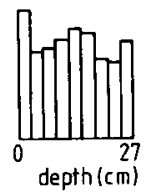

Fig. 4. Root distribution of maize roots, three weeks after emergence, in relation to soil mechanical resistance $(C R)$ and phosphate availability $\left(\mathbf{P}_{\mathbf{w}}\right)$.

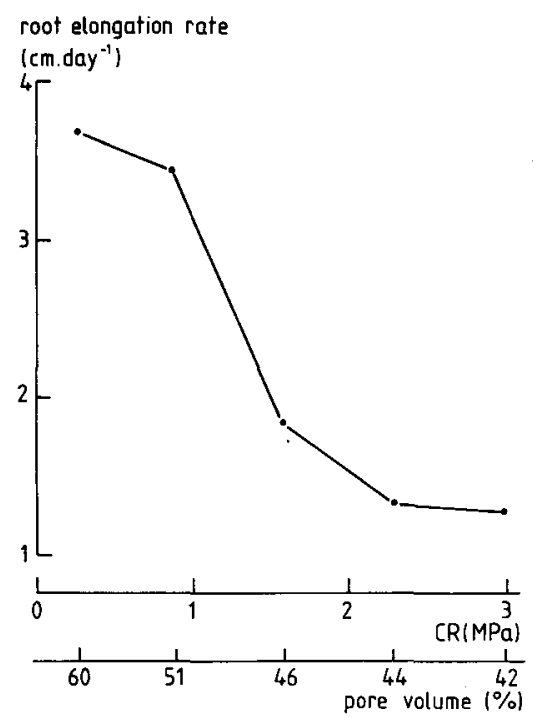

Fig. 5. Relation between the elongation rate of main roots of maize and the mechanical resistance (CR) of the soil.

Table 1. Influence of mechanical impedance on the inclination of main root axes of maize.

\begin{tabular}{|c|c|c|c|}
\hline $\begin{array}{l}\text { Penetrometer } \\
\text { resistance } \\
\text { (MPa) }\end{array}$ & $\begin{array}{l}\text { Number of } \\
\text { root } \\
\text { segments }\end{array}$ & $\begin{array}{l}\text { Average } \\
\text { length } \\
\text { (cm) }\end{array}$ & $\begin{array}{l}\text { Angle to } \\
\text { vertical } \\
\left({ }^{\circ}\right)\end{array}$ \\
\hline $\begin{array}{l}0.3 \\
3\end{array}$ & $\begin{array}{l}42 \\
45\end{array}$ & $\begin{array}{l}6.0 \\
9.0\end{array}$ & $\begin{array}{l}60 \\
70.5\end{array}$ \\
\hline
\end{tabular}

Neth. J. agric. Sci. 30(1982) 


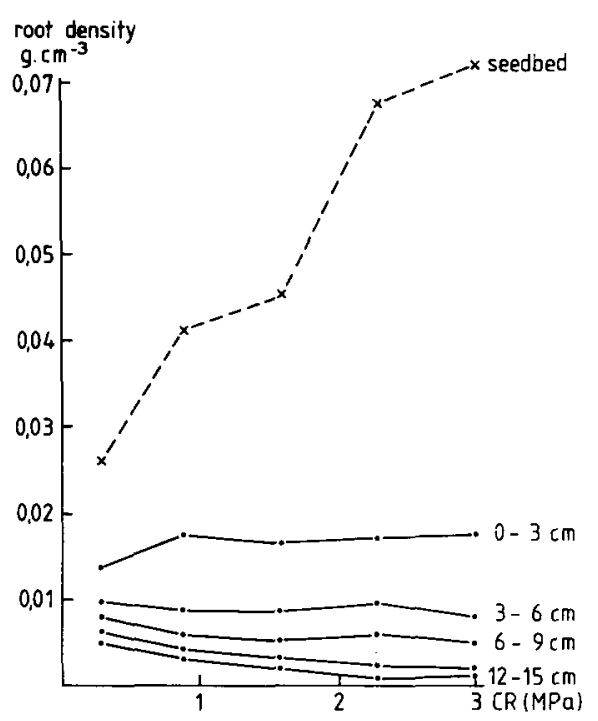

Fig. 6. Root density of maize in different soil layers in relation to cone resistance below the seedbed.

ditions. The average angle to the vertical of the main axes is calculated from the length of segments of main root axes from a $3-\mathrm{cm}$ thick upper soil layer. Table 1 shows that roots grow steeper downwards in a loose soil than in a dense soil. Thirdly, root distribution is also influenced by relative differences in mechanical resistance different parts of the root system encounter. There is a preference of roots to grow in a layer with a low mechanical resistance rather than in a layer with a higher mechanical resistance which is clearly demonstrated in Fig. 6. As can be learned from the first experiment, the amount of roots grown in a $1-\mathrm{cm}$ thick loose seedbed strongly increases with increasing mechanical resistance of the soil below the seedbed. Except for the first layer, root weight in the soil layers below the seedbed is negatively correlated with the mechanical resistance of the

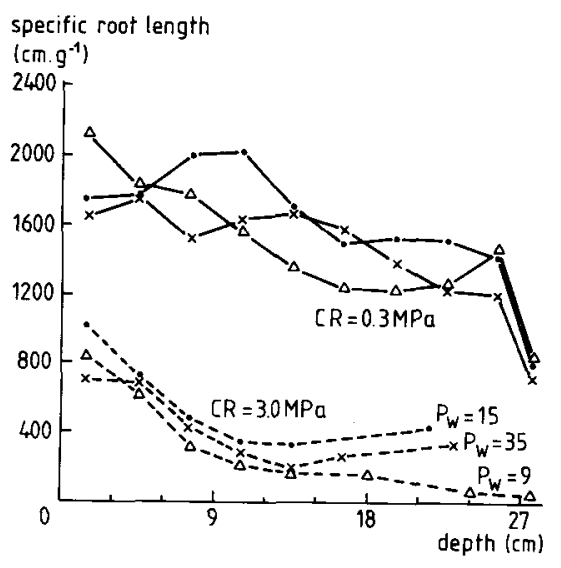

Fig. 7. Influence of mechanical resistance (CR) on root length of maize per unit root weigth at different soil depths, and different phospate availabilities $\left(\mathbf{P}_{\mathrm{w}}\right)$. 
Table 2. Influence of mechanical resistance on the development of lateral roots of maize.

\begin{tabular}{|c|c|c|c|c|}
\hline \multicolumn{3}{|c|}{ First order laterals per gram total root } & \multicolumn{2}{|c|}{ First order laterals per $\mathrm{cm}$ main axis } \\
\hline $\begin{array}{l}\text { resistance } \\
\text { (MPa) }\end{array}$ & $\begin{array}{l}\text { weight } \\
\text { (g) }\end{array}$ & $\begin{array}{l}\text { total } \\
\text { lenght }(\mathrm{cm})\end{array}$ & number & total length $(\mathrm{cm})$ \\
\hline 0.3 & 0.40 & 1205 & 9.9 & 14.4 \\
\hline 3.0 & 0.47 & 499 & 6.1 & 9.3 \\
\hline
\end{tabular}

layer itself. In pots without a seedbed such differences in mechanical resistance between layers are still present and imposed by the water regime applied.

Although mean water content is kept constant, daily water gift at the top of the pot results in a temporarily sharp increase in water content of the top layers. As a consequence mechanical resistance temporarily decreases in these layers.

Root morphology. Although fresh weight of the root system is not influenced by the mechanical resistance, root morphology changes considerable (Fig. 7). Unimpeded roots are much thinner than roots grown at a high mechanical resistance. Near the bottom of the pot differences are much smaller because here young unbranched root tips accumulate. There is no distinct influence of phosphate supply on root morphology. Just like the total weight, the weight of laterals per gram root is not influenced by the mechanical resistance (Table 2). The total length of the laterals per gram root, however, is strongly decreased concomitantly with an increased diameter. The decrease in total lateral root length per $\mathrm{cm}$ main axis at increased mechanical resistance is mainly caused by a decreased lateral root number, whereas the length of the individual lateral roots is not influenced.

\section{Shoot growth}

Under optimal light conditions shoot growth appears to be clearly dependent on phosphate availability as well as on the mechanical resistance of the soil (Fig. 1). At low light intensity shoot growth is much smaller than at high light intensity and hardly influenced by phosphate supply or soil mechanical resistance. (Fig. 3 ). The fairly even distribution of roots with depth and the much longer and thinner root system at a low mechanical resistance allows a better uptake of nutrients and water and therefore a better shoot growth. When it is supposed that at a high mechanical resistance the uptake of nutrients or water is limiting shoot growth, the strongest relative effect of mechanical resistance on shoot growth would be expected at the lowest $P$ level, according to the law of diminishing returns. However, the strongest effect of mechanical resistance on shoot growth is observed at the highest $\mathrm{P}$ level, which is close to optimal for shoot growth. A possible explanation for this contradiction is that at a high phosphate supply, another factor is limiting shoot growth when root development is impeded by a high mechanical resistance. 


\section{F. R. BOONE AND B. W. VEEN}

To get insight into the nature of the limiting factor the mineral contents of the shoot have been analysed as well as the relation between the shoot growth and its mineral contents.

\section{Mineral content and shoot growth}

Except at low phosphate supply, total nitrogen content of the shoot is somewhat higher at a low mechanical resistance than at a high mechanical resistance (Fig. 8). All levels are considered to be optimal for shoot growth (Warncke \& Barber, 1974).

The potassium content of the shoot is much stronger influenced by soil density than the nitrogen content: the higher the mechanical resistance, the lower the potassium content. Also the phosphate supply has a clear effect: a high phosphate supply decreases the potassium content of the shoot. At this phosphate supply and a medium or high mechanical resistance the potassium content is considered suboptimal for shoot growth (Ismunadji \& Dijkshoorn, 1971).

The phosphate content of the shoot is strongly influenced by the phosphate
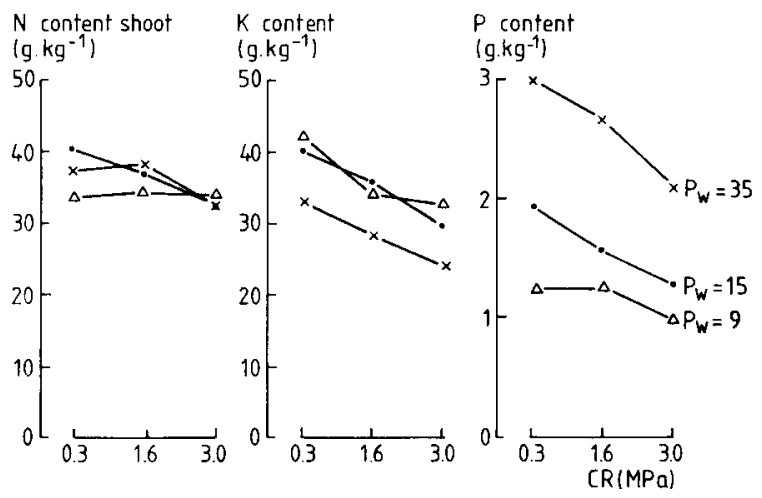

Fig. 8. Mineral contents of maize shoots, three weeks after emergence of plants grown in soil with different mechanical resistance (CR) and different phosphate supply $\left(\mathrm{P}_{\mathrm{w}}\right)$.

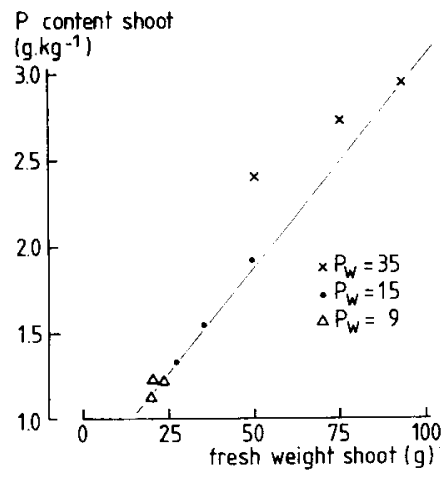

Fig. 9. Relation between $P$ content and shoot growth of maize. 


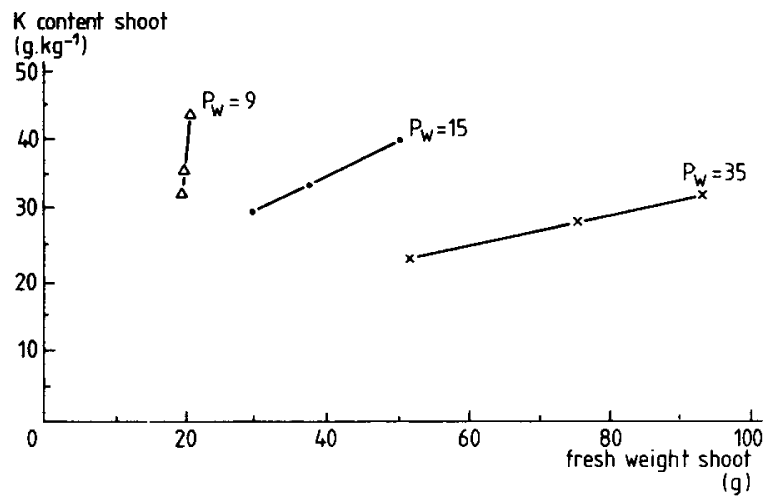

Fig. 10. Relation between shoot growth and $\mathrm{K}$ content of maize shoots, at different phosphate supply levels $\left(\mathrm{P}_{\mathrm{w}}\right)$.

supply of the soil. At a low phosphate supply there is hardly any influence of soil density, but at a high phosphate supply the mechanical resistance has a clear negative effect on the phosphate content. The two lower phosphate supply levels are considered suboptimal for shoot growth (Jones, 1967).

At the lowest and middle phosphate supply level a close relation exists between shoot fresh weight and shoot phosphate content (Fig. 9). At the highest phosphate level combined with the medium or high mechanical resistance, shoot growth is less than expected from the phosphate content. This suggest that at the highest phosphate supply and impeded root development another factor than phosphate limits shoot growth. At the lowest phosphate supply shoot growth is independent of the potassium content (Fig. 10). At increasing phosphate supply, however, an increasing effect of potassium content on shoot growth can be observed, indicating that the availability of potassium becomes a limiting factor for shoot growth.

\section{Root developement and ion uptake}

The uptake of total nitrogen, potassium and phosphorus between two weekly harvests is calculated per unit of root weight, root length and root surface area (Table 3). At a high phosphate supply the uptake of N, P and K per unit of root length is independent of the mechanical resistance suggesting that the rate of ion uptake depends on root length. At a lower phospate supply the relation between ion uptake and one of the root parameters is less clear.

From Fig. 4 it appears that in a dense soil there is a strong accumulation of roots in the upper soil layers. In these layers root densities of up to $20 \mathrm{~cm} / \mathrm{cm}^{3}$ were found, which considerably exceeds root densities normally found in a tilled field (Mengel \& Barber, 1974). Fig. 11 shows the relative increase in root density between two harvests in relation to the root density present at the first harvest. At low phosphate supply the relative increase is low and independent of the root density present at the first harvest. At high phosphate supply, however, the relative increase is high at low root intensities but decreases at high root densities to the same low level found at a low phosphate supply. This suggest that root 
Table 3. Ion uptake of maize in the 7-days period between two harvests in relation to three root parameters.

\begin{tabular}{|c|c|c|c|c|c|c|c|c|c|c|}
\hline \multirow{2}{*}{$\begin{array}{l}\text { Mechanical } \\
\text { resistance } \\
(\mathrm{MPa})\end{array}$} & \multirow{2}{*}{$\begin{array}{l}\text { Phosphate } \\
\text { supply } \\
\left(P_{w}\right)\end{array}$} & \multicolumn{3}{|c|}{$P$} & \multicolumn{3}{|c|}{$\mathrm{K}$} & \multicolumn{3}{|c|}{$\mathrm{N}$} \\
\hline & & $\mu \mathrm{g} / \mathrm{cm}$ & $\mu \mathrm{g} / \mathrm{cm}$ & $\mu \mathrm{g} / \mathrm{g}$ & $\mu \mathrm{g} / \mathrm{cm}$ & $\mu \mathrm{g} / \mathrm{cm}$ & $\overline{\mathrm{mg} / \mathrm{g}}$ & $\mu \mathrm{g} / \mathrm{cm}$ & $\mu \mathrm{g} / \mathrm{cm}$ & $\mathrm{mg} / \mathrm{g}$ \\
\hline 0.3 & 9 & 0.6 & 0.07 & 9 & 1.36 & 14.5 & 1.95 & 1.01 & 10.8 & 1.42 \\
\hline 3.0 & 9 & 1.1 & 0.08 & 7 & 2.52 & 17.2 & 1.47 & 2.56 & 17.5 & 1.49 \\
\hline 0.3 & 15 & 18.1 & 1.97 & 271 & 4.19 & 45.7 & 6.28 & 4.41 & 48.1 & 6.63 \\
\hline 3.0 & 15 & 10.4 & 0.76 & 70 & 3.74 & 27.4 & 2.50 & 3.11 & 22.7 & 2.08 \\
\hline 0.3 & 35 & 52.0 & 5.69 & 780 & 5.93 & 64.8 & 8.90 & 6.54 & 71.6 & 9.80 \\
\hline 3.0 & 35 & 52.0 & 3.40 & 278 & 5.40 & 35.3 & 2.89 & 6.87 & 44.9 & 3.68 \\
\hline
\end{tabular}

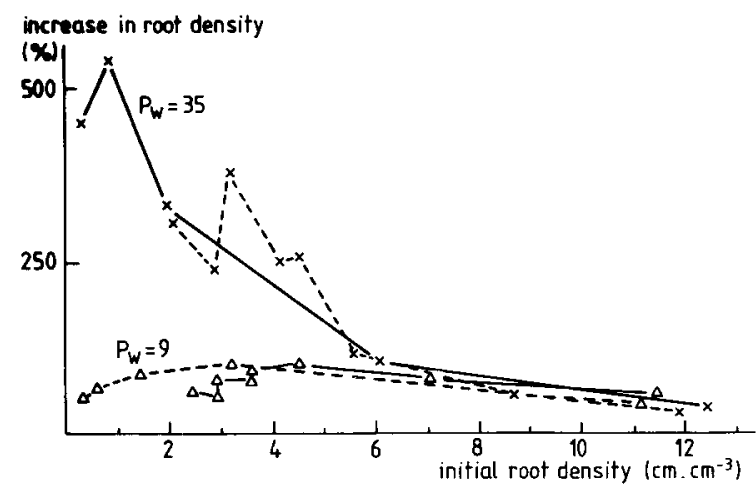

Fig. 11. Influence of root density on the relative increase in root length in the periode $2-3$ weeks after emergence, at two levels of phosphate supply $\left(\mathrm{x}=\mathrm{P}_{\mathrm{w}} 35, \Delta=\right.$ $\left.P_{w} 9\right)$, and two levels of mechanical resistance $(-0.3 \mathrm{MPa} ; \ldots . .$. 3.0 MPa).

growth is limited by a factor, presumably $\mathrm{K}^{+}$, that is removed from those densely rooted layers. In recent experiments chemical analysis of the upper soil layers revealed that main elements are quickly exhausted particularly in pots with low concentrations of these elements (Veen, unpublished results). Under these conditions nutrients are taken up from lower soil layers, and uptake is expected to be related to roots in only this part of the soil.

\section{Discussion}

The shape of the curve relating root elongation rate and soil mechanical resistance (Fig. 5) is comparable with the curve published by Russell \& Goss (1974) for the relation between root elongation rate of barley and the external pressure applied on 1-mm glass beads between which roots are growing. The figure shown is also comparable with the curves for roots grown in soil of Taylor \& Ratliff (1969a) for cotton and peanuts and Bradford (1980) for pea.

The pressure potential created by the osmotic potential within the root cells is considered as the driving force for root elontagion (Pfeffer, 1893; Taylor \& Rat- 
liff, 1969b). Part of this force is used to overcome cell wall resistance and part to displace the external medium. When external pressure is applied to roots, appreciable relative to turgor pressure, the growth reduction can be attributed to a direct effect of this external pressure counteracting the turgor within the cell. Resistances low relative to turgor pressure $(0-50 \mathrm{KPa})$, however, also result in severe growth reductions (Goss, 1977) that cannot be explained in simple physical terms. Goss \& Russell (1981) suggest that a physiological mechanism is responsible for the growth reduction at low mechanical resistance. The existence of these two mechanisms can explain the non-linear relation between root growth and the pressure applied. Nevertheless, there are at least two other factors involved in the relation between root extension growth and penetrometer resistance in soil. In a relatively loose soil the flexible roots take the easiest way through the continuous big pores and planes of weakness, thereby experiencing a mechanical resistance much smaller than measured by a penetrometer. These big pores gradually disappear at compaction (Boone, 1976), resulting in a disproportionate increase in impedance of the roots as compared with penetrometer values. A second factor is the daily watering of the pots. It is known that in a dense soil with a high mechanical resistance a change in water content has a much larger effect on mechanical resistance than in a loose soil with a low mechanical resistance (Boone et al., 1978). Therefore especially in a dense soil mechanical resistance temporarily decreases after water supply, mainly in the top layer. The bending of the curve of Fig. 5. between 1.6 and $3.0 \mathrm{MPa}$ may be partly due to the effect of temporary decreases in mechanical soil resistance after water supply.

The external pressure applied on glass beads can be regarded as an estimate of the pressure actually experienced by roots growing between the glass beads (Goss, 1977; Veen, unpublished results). This pressure, however, is about 40 times smaller than the soil penetrometer resistance with a comparable effect on root growth, although in soil the difference between cone resistance and the pressure the roots experience appeared to be a factor 3.8 (Whiteley et al., 1981). Roots growing in a bed of ballotini, percolated with aerated nutrient solution, seem to react much more sensitive to mechanical impedance than roots growing in soil. Roots growing in ballotini with an externally applied pressure are distorted when entering the pores between the glass beads in such a way that the pores are more or less closed (Russell, 1977). Although in these experiments an aerated nutrient solution is circulated through the rooting medium, the access of oxygen to the roots may be obstructed. Tackett \& Pearson (1964) and Hopkins \& Patrick (1969) report a synergistic effect of a low oxygen concentration and mechanical impedance on root growth. It is therefore suggested that a low oxygen supply to roots grown between ballotini beads is an alternative explanation for the severe reduction of root growth at low mechanical impedance.

An extensive literature is available on the influence of mechanical impedance on root growth and root morphology. It is generally accepted that impedance decreases longitudinal growth of roots (e.g. Barley, 1962; Taylor \& Ratliff, 1969a; Russell \& Goss, 1974) and increases root diameter (Russell \& Goss, 
1974; Peterson \& Barber, 1981), but there is no unanimity about the influence of impedance on root branching. Our results indicate that under our experimental conditions the number of laterals per main axis decreases at increasing mechanical impedance. A number of authors (Barley, 1962; Ellis et al., 1977; Goss, 1977; Schumacher \& Smucker, 1981; Peterson \& Barber, 1981) report an increase in lateral branching, while others (Fox et al., 1953; Rosenberg \& Willits, 1962; Schuurman, 1965) report a restricted root branching at an increased mechanical impedance. An increase in root branching at increased mechanical impedance generally is found in artificial substrates (ballotini, sand) when existing pores are large enough to allow unimpeded growth of laterals. In a dense soil, however, outgrowth of laterals may be obstructed because most pores are smaller than the diameter of the laterals. Another phenomenon obscuring the influence of a high mechanical resistance on root braching is the fact that laterals emerge much closer to the a pex of the main axes than at a low mechanical resistance (Barley, 1962; Russell \& Goss, 1974). For the study of the influence of mechanical impedance on root branching basal segments, on which laterals have fully developed, should be compared.

In our experiments the length of laterals is the same at high and low mechanical resistance (Table 2), which does not mean, however, that growth of laterals has not been reduced. Growth of impeded lateral roots should not be compared with unimpeded lateral roots, but with unimpeded lateral roots with impeded main axes, under which conditions lateral root growth is strongly increased (Goss, 1977).

When nutrients are uneven distributed in a soil, growth of the root system preferently occurs in places well supplied with nutrients (Drew, 197.5). The root system itself can develop such an uneven distribution of nutrients. As shown a high mechanical resistance results in a tremendous accumulation of roots in the surface layers. Under limiting conditions this can give rise to the exhaustion of these layers. In the experiments described phosphate but also potassium are the limiting factors at high root densities. The consequence is that the uptake of phosphate and potassium cannot be attributed to the root system as a whole but only to that part which was able to take up the limiting element. Not only specific characteristics (e.g. root weight, root length and root surface area) of the roots in different soil layers, but also the specific conditions in these layers must be taken into consideration.

\section{Acknowledgement}

The authors wish to thank Mr B. Kroesbergen and Mr A. Boers (Tillage Laboratory) and $\mathrm{Mr} \mathrm{J}$. Th. Locher (Centre for Agrobiological Research) for carrying out the experiments that included a vast amount of measurements 


\section{MECHANICAL RESISTANCE AND P SUPPLY: INFLUENCE ON MAIZE ROOTS}

\section{References}

Barley, K. P., 1962. The effects of mechanical stress on the growth of roots. J. exp. Bot. 13: 95-110.

Böhm, W., 1979. Methods of studying root systems. Ecological Studies, Volume 33. Springer-Verlag, Berlin, $188 \mathrm{pp}$.

Boone, F. R., J. Bouma \& L. A. H. de Smet, 1978. A case study on the effect of soil compaction on potato growth in a loamy sand soil. 1. Physical measurements and rooting patterns. Neth. J. agric. Sci. 26: 405-420.

Boone, F. R., S. Slager, R. Miedema \& R. Eleveld, 1976. Some influences of zero tillage on the structure and stability of a fine-textured river levee soil. Neth. J. agric. Sci. 24: 105-119.

Bradford, J. M., 1980. The penetration resistance in a soil with well-defined structural units. J. Soil Sci. Soc. Am. 44: 601-606.

Drew, M. C., 1975. Comparison of the effects of localized supply of phosphate, nitrate, ammonium and potassium in the growth of the seminal root system and the shoot in barley. New Phytol. 75: 479-490.

Ellis, F. B., J. G. Elliot, B. T. Barnes \& K. R. Howse, 1977. Comparison of direct drilling, reduced cultivation and ploughing on the growth of cereals. 2. Spring barley on a sandy loam soil: soil physical conditions and root growth. J. agric. Sci. 89: 631-642.

Fox, F. L., J. E. Weaver \& R. C. Lipps, 1953. Influence of certain soil profile characteristics upon the distribution of roots of grasses. A gron. J. 45: 583-589.

Goss, M. J., 1977. Effects of mechanical impedance on root growth in barley (Hordeum vulgare L.) I. Effects on the elongation and branching of seminal root axes. J. exp. Bot. 28: 96-111.

Goss, M. J. \& R. S. Russell, 1980. Effects of mechanical impedance on root growth in barley (Hordeum vulgare L.). III. Observations on the mechanism of response. J. exp. Bot. 31: 577-588.

Hopkins, R. M. \& W. H. Patrick Jr., 1969. Combined effects of oxygen concentration and soil compaction on root penetration. Soil Sci. 108: 408-413.

Ismunadji, M. \& W. Dijkshoorn, 1971. Nitrogen nutrition of rice plants measured by growth and nutrient content in pot experiments. I. Ionic balance and selective uptake. Neth.J. agric. Sci. 19:223226.

Jones, J. B. Jr., 1967. Interpretation of plant analysis for several agronomic crops. In: Soil testing and plant analysis, p. 49-58. Soil Science Society of America, Madison. Wisc.

Mengel, D. B. \& S. A. Barber, 1974. Development and distribution of the corn root system under field conditions. A gron. J. 66: 341-344.

Newman, E. J., 1961. A method for estimating the total length of roots in a sample. J. appl. Ecol. 3: $139-145$

Paauw, F. van der, 1971. An effective water extraction method for the determination of plant-available soil phosphorus. Pl. \& Soil 34: 467-481.

Peterson, W. R. \& S. A. Barber. 1981. Soybean root morphology and K-uptake. Agron. J. 73: 316319.

Pfeffer, W., 1893. Druck und Arbeitsleistung durch wachsende Pflanzen. Abh. Sächs. Akad. Wiss. 33: 235-474.

Rosenberg, N. J. \& N. A. Willets. 1962. Yield and physiological response of barley and beans grown in artificially compacted soil. Soil Sci. Soc. Am. Proc. 26: 78-82.

Russell, R. S., 1977. Plant root systems. Mc.Graw-Hill, London, 281 pp.

Russell, R. S. \& M. J. Goss, 1974. Physical aspects of soil fertility. The response of roots to mechanical impedance. Neth. J. agric. Sci. 22: 305-318.

Schumacher, T. E. \& A. J. M. Smucker, 1981. Mechanical impedance effects on oxygen uptake and porosity of drybean roots. Agron. J. 43: 51-55.

Schuurman, J. J., 1965. Influence of soil density on root development and growth of oats. Pl. \& Soil 22: 352-374.

Tackett J. L. \& R. W. Pearson, 1964. Oxygen requirement for cotton seedling root penetration of compacted soil cores. Soil Sci. Soc. Am. Proc. 28: 600-604.

Taylor, H. M. \& L.F. Ratliff, 1969a. Root elongation rates of cotton and peanuts as a function of soil strength and soil water content. Soil Sci. 108: 113-119.

Neth. J. agric. Sci. 30(1982) 


\section{F. R. BOONE AND B. W. VEEN}

Taylor, H. M. \& L. F. Ratliff, 1969b. Root growth pressures of cotton, peas and peanuts. Agron. J. 61: 398-402.

Warncke, D. D. \& S. A. Barber, 1974. Root development and nutrient uptake by corn grown in solution culture. Agron. J. 66: 514-516.

Whiteley, G. M., W. H. Utomo \& A. R. Dexter, 1981. A comparison of penetrometer pressures and the pressures exterted by roots. Pl. \& Soil 61: $351-364$. 